\title{
A DANÇA NA PERSPECTIVA DE UM JOGO DIGITAL ${ }^{1}$
}

Recebido em: 19/11/2017

Aceito em: 17/05/2018

\author{
Paola Luzia Gomes Prudente ${ }^{2}$ \\ Universidade Federal de Minas Gerais (UFMG) \\ Belo Horizonte - MG - Brasil
}

RESUMO: O presente artigo insere-se no campo dos estudos sobre a relação entre dança e jogos digitais e tem como objetivo analisar os jogos digitais de dança buscando compreender, por meio de uma revisão literária, como a dança se constitui na perspectiva de um jogo digital. Ao se voltar o olhar para o contexto específico dos jogos digitais de dança, percebe-se que esses recursos tecnológicos já expressam novas tendências, ampliando, sobremaneira, as possibilidades de experiências enquanto corpos dançantes. Os jogos digitais de dança proporcionam conhecimento do corpo, de suas habilidades, potencialidades e limites podendo chegar a transformação e criação de novas formas de se movimentar e consequentemente novas formas de dançar.

PALAVRAS CHAVE: Jogos de Vídeo. Dança. Atividades de Lazer.

\section{DANCE: AN OVERVIEW FROM DIGITAL GAMES}

ABSTRACT: The following article is part of the studies about the connection between dance and digital games and its main purpose is to analyze the digital dance games in order to comprehend it from literary review, the way dance can be perceived from the perspective of a digital game. By taking a close look at a specific context of digital dance games, it is possible to realize that these technological resources present new trends, expanding specially the possibilities of experiences while dancing bodies. The digital dance games provide body knowledge and its skills, its strengths and limits allowing transformation and creation of new ways of moving oneself and thus new ways of dancing.

KEYWORDS: Video Games. Dancing. Leisure Activities.

\footnotetext{
${ }^{1}$ Artigo premiado no $29^{\circ}$ Encontro Nacional de Recreação e Lazer (ENAREL), realizado em Caruaru/PE em 2017.

${ }^{2}$ Licenciada e Bacharel em Educação Física pela Universidade de Itaúna. Mestre em Educação pela Universidade de Itaúna. Doutoranda em Estudos do Lazer pela Universidade Federal de Minas Gerais.
} 


\section{Escolhendo o Jogo}

O presente artigo insere-se no campo dos estudos sobre a relação entre dança e jogos digitais. Segundo Finco e Fraga (2013) os jogos digitais são considerados uma das mais expressivas práticas de entretenimento do século XXI, atingindo um público de diversas idades e de ambos os sexos. Ainda nesse sentido, Assunção (2012) nos mostra que os jogos digitais compõem a mídia de entretenimento que emergiu fortemente em função das tecnologias digitais, alcançando grande popularidade como fonte recreativa mundial.

Segundo Gomes (2015) diversas práticas sociais de lazer, incluindo os jogos digitais, foram redimensionadas e apropriadas pelas indústrias culturais e criativas e se vincularam ao lazer, entendido neste estudo como

[...] uma necessidade humana e como uma prática social complexa e historicamente situada, que se manifesta em diferentes contextos de acordo com os sentidos e significados (re) produzidos culturalmente pelas pessoas em suas relações com o mundo. Seguindo essa interpretação, o lazer é uma dimensão da cultura caracterizada pela vivência lúdica de manifestações culturais no tempo/espaço social. Assim compreendido, o lazer baseia-se na articulação de três elementos fundamentais: a ludicidade, as manifestações culturais e o tempo/espaço social (GOMES, 2015, p.366).

Os jogos digitais, as experiências virtuais, a dança e a expressão corporal, podem ser, antes de mais nada, considerados manifestações culturais de lazer, sendo estas compreendidas na perspectiva de

[...] práticas sociais vivenciadas como fruição da cultura e são passíveis de conflitos, contradições e relações de poder. Elas detêm sentidos e significados únicos para as pessoas, para diferentes grupos sociais, para as instituições e para a sociedade que as vivencia social, histórica e culturalmente (GOMES, 2015, p.366). 
Dentre as possibilidades de manifestações culturais de lazer destacam-se neste estudo os jogos digitais de dança, que atraem um número crescente de adeptos e possibilita a interação da dança com as novas tecnologias.

Apesar desse crescimento contínuo, é fundamental destacar que a produção acadêmica que problematiza a dança em outras possibilidades de apropriação, para além das abordagens artísticas e educacionais, ainda é incipiente (CHAVES; SILVA, 2017). São justamente nessa lacuna que se insere as intenções desse trabalho, que por meio de uma revisão literária, tem como objetivo identificar os jogos digitais de dança, buscando compreender como a dança se constitui na perspectiva de um jogo digital.

\section{A Dança}

A dança é uma forma de expressão capaz de projetar, no espaço e tempo as mais variadas potencialidades criativas do ser humano (NANNI, 1995; GARCIA e HASS, 2003). O homem por sua forma natural de se expressar, tem necessidade de comunicar-se, seja verbalmente ou fisicamente (MINELLO, 2006). Em diferentes situações o homem faz uso de movimentos para se expressar; movimentos estes que podem ser leves ou fortes, diretos ou flexíveis, lentos ou súbitos, controlados ou livres. E estes movimentos dão base para a criação de novas possibilidades de movimentos e expressões corporais (LABAN, 1990).

Acredita-se que a dança está presente desde a era primitiva, ou seja, desde que o homem existe, existe a dança. Antes mesmo de usar as palavras o homem já fazia movimentos corporais como forma de expressar seus sentimentos (GARCIA; HASS, 2003). De todas as artes, a dança é 
[...] a única que dispensa materiais e ferramentas, dependendo só do corpo. Por isso, diz-na a mais antiga, aquela que o ser humano carrega dentro de si desde tempos imemoriais. Antes de polir a pedra, construir abrigo, produzir utensílios, instrumentos e armas, o homem batia os pés e as mãos ritmicamente para se aquecer e comunicar. Assim, das cavernas à era do computador, a dança fez e continua fazendo história (PORTINARI, 1989, p 11).

Marques (2010) escreve que, ao contrário de uma visão histórica ingênua de que a dança não passa de uns passinhos a mais ou a menos na vida das pessoas, hoje não podemos mais ignorar o papel social, cultural e político do corpo em nossa sociedade. Corpo esse que $[. .$.$] pode ser somado a uma série de recursos tecnológicos que ampliam$ as condições e significações do mesmo" (SANTOS, et al, 2012, p. 3).

Para Laban (1990), a dança é uma forma desencadeadora de movimento, e é, como todas as artes, uma tentativa de resposta às questões colocadas por determinadas épocas. Ela reflete o que os homens estão buscando em sua forma de vida.

Fragoso e Brasileiro (2015) lembram que durante toda a vida nos deparamos com a dança, seja em casa, em festas, nas igrejas, nas ações sociais, em parques e na sociedade de uma forma geral. A dança acontece por vários fatores culturais, que vão sendo construídos ao longo do tempo e reflete especificidade de cada local, criando significados de acordo com o contexto histórico, político e social no qual está inserida.

Nesse sentido, “a conexão da dança com os vários campos da vida são alvo de constante reflexão e experimentação prática na contemporaneidade” (MENDES, 2013, p. 20). Ela se faz presente nas mais diversas relações - com o jogo, com a arte, com a educação etc. - e, portanto, não seria diferente que a dança também emergisse na perspectiva tecnológica, que se faz tão presente na nossa sociedade.

Segundo Amoroso (2004) os artistas e teóricos que trabalham com a relação dança-tecnologia afirmam que a tecnologia digital amplia e expande as possibilidades 
do corpo humano apesar de reconhecerem um receio da substituição do corpo que perpassa o mundo da dança. Entretanto, para a mesma autora, o que ocorre não é uma substituição ou uma dominação; o corpo é o primeiro a buscar compreender essa tecnologia e a interagir com ela de forma criativa. Amoroso (2004) afirma, que na interação entre o corpo humano e a tecnologia não humana há uma relação de igualdade, na qual a hierarquia não se faz presente. No entanto, mesmo os defensores desse novo estilo de dança têm a preocupação de esclarecer a intenção da utilização de recursos da tecnologia digital na dança exatamente porque a tecnologia na dança não vem para substituir ou matar o corpo, mas sim para ampliá-lo.

Nessas interações entre o corpo e a tecnologia, a linguagem do corpo cede espaço para a linguagem tecnológica [...]. É o corpo híbrido homem/máquina. E aqui está um ponto importante para o entendimento dessa transformação na dança: o corpo passa a se expressar por outra via que não a da expressão corporal-sinestésica, mas sim através da tecnologia digital que medeia os corpos e que coloca nessa mediação a sua própria linguagem (AMOROSO, 2004, p. 24).

Na perspectiva da dança há diversas possibilidades de a tecnologia entrar em cena, quando por exemplo: o bailarino deixa de aparecer no espaço cênico, ao vivo, para aparecer em uma tela; o que se vê no palco escuro é um holograma computadorizado mostrando movimentos digitais; acontece o estudo do movimento, elaboração, arquivo e transmissão de coreografias por meio dos computadores. Também percebemos uma transformação da natureza da dança a partir da interação do corpo com a tecnologia digital quando sensores captam os impulsos humanos, transformando-os em sons e imagens, criando assim, espaços interativos que possibilitam por exemplo, dançar a partir da experiência de um jogo digital (AMOROSO, 2004). 


\section{Jogo Digital}

Os jogos digitais são artefatos de grande fascínio social, econômico e tecnológico (MENDES, 2006). Esse fascínio se dá pelos mais diversos aspectos, entre eles: o volume de venda no país; a relação diretamente proporcional entre a evolução das tecnologias da informática e o aparecimento e evolução dos jogos digitais, além do crescente número de seres humanos que vivenciam.

Mendes (2006) ressalta, como um dos fatores de fascínio social, o processo de subjetivação, onde esses seres humanos são convencidos “[...] por meio das histórias, das narrativas e dos personagens dos jogos, dos prazeres, dos riscos [...] a participar dos jogos e das comunidades de jogadores" (p.17). Processo de subjetivação entendidos pelo autor como aquelas “[...] conexões que nos ligam a outros humanos, a saberes e a relações de poder que nos rodeiam, constituindo a nós como tipos específicos de sujeitos” (FOUCAULT, 1996 apud MENDES, 2006 p. 17).

Muller e Cruz (2016), ao tratar o jogo digital como artefato de fascínio social também elenca a criação de comunidades com comportamentos e interesses comuns, além da criação de cursos voltados para o desenvolvimento de games e até o surgimento de novas profissões como a profissionalização do jogador de game.

Com relação ao fascínio econômico e tecnológico, Fardo (2013) nos mostra que em quase todas as casas nos EUA existe pelo menos um dispositivo que possibilite rodar jogos digitais (computador, console, smartphone) e a idade média do jogador é de trinta anos. No Brasil em 2013, cerca de 23\% dos brasileiros eram jogadores assíduos ou casuais, o que correspondia a aproximadamente 45 milhões de jogadores (FARDO, 2013). 
De acordo com dados da Superintendência da Zona Franca de Manaus (Suframa), o número de consoles fabricados no Brasil cresceu 92\% em 2013, e ao longo do mesmo ano foram vendidas para as lojas mais de 1,36 milhão de unidades em todo o país. Ainda no ano de 2013 o faturamento do setor foi de quase R $\$ 870$ milhões, ultrapassando o faturamento de PCs desktop, de câmeras digitais, de monitores e de computador $\mathrm{LCD}^{3}$.

Assim como diversos setores produtivos de todo o país, no ano de 2014, o setor dos jogos digitais foi impactado pelas dificuldades econômicas impostas pelo cenário nacional e internacional. Segundo José Jorge do Nascimento Júnior - coordenador Geral de acompanhamento de projetos industriais da Suframa, os números são um reflexo da readequação dos investimentos das empresas do setor e as expectativas do polo industrial eram positivas. Vale ressaltar, que mesmo em crise, foram produzidos cerca de um milhão de unidades de consoles, com um faturamento de mais de 633 milhões ${ }^{4}$.

Segundo um estudo publicado pelo instituto SuperData, o mercado de game mundial movimentou US\$ 65 bilhões em $2015^{5}$. Ainda no ano de 2015, o NPD Group, $8^{\mathrm{a}}$ maior empresa de pesquisa de mercado do mundo, constatou que os games estão entre as principais atividades dos adolescentes, jovens e adultos no Brasil: cerca de $82 \%$ da população do país, entre 13 e 59 anos, joga algum tipo de game nas mais diversas plataformas, sejam PCs, consoles, dispositivos mobile ou portáteis ${ }^{6}$.

\footnotetext{
3 Informação disponível em: https://g1.globo.com/tecnologia/games/noticia/2014/02/numero-devideogames-fabricados-no-brasil-cresce-92-em-2013.html. Acesso em: 19 abr. 2015

4 Informações concedidas pelo executivo à Jornal Folha de São Paulo, por e-mail. Disponível em: $<$ https://www1.folha.uol.com.br/tec/2015/02/1594096-fabricacao-de-videogames-no-brasil-teve-quedade-25-em-2014.shtml> Acesso em: 10 abr. 2016

${ }^{5}$ Notícia disponível em: http://www.ecommercebrasil.com.br/noticias/industria-de-jogos-eletronicos-umsetor-em-ascensao-no-brasil/. Acesso em 23 de março de 2018.

${ }^{6}$ Notícia disponível em: <http://www.npd.com/wps/portal/npd/us/news/press-releases/2015/new-reportfrom-the-npd-group-provides-in-depth-view-of-brazils-gaming-population/> . Acesso em: 23 mar.2018.
} 
Já em 2016, o mercado global de jogos digitais faturou aproximadamente US\$ 99,6 bilhões. A China registrou uma receita aproximada de US\$24,3 bilhões para o setor, enquanto os EUA ficaram em segundo com US\$ 23,59 bilhões. O Brasil, por sua vez, subiu uma posição no ranking mundial, se comparado ao ano de 2015 , tendo ultrapassado a Austrália e ficado em $12^{\circ}$ lugar, com US\$ 1,27 bilhão. Na América Latina, o Brasil lidera o ranking, seguido de perto pelo México, como nos mostra os dados do relatório anual do mercado global de games ${ }^{7}$.

Segundo o mapeamento da indústria brasileira de jogos digitais, que foi realizado com o intuito de apresentar um panorama atual deste setor, o mercado global de jogos digitais movimentou US\$ 65,7 bilhões em 2013, e deve chegar a US\$ 89 bilhões em 2018, projetando uma taxa de crescimento de $6,3 \%$ ao ano. Como comparação, o movimento da indústria de filmes de entretenimento foi de US\$ 88,2 bilhões em 2013 (US\$ 38,7 bilhões de cinema e US\$ 49,5 bilhões de vídeo doméstico) e a projeção para 2018 é US\$ 110 bilhões, resultado de uma taxa de crescimento projetada de $4,5 \%$ ao ano $^{8}$.

Ao se tratar da América Latina e principalmente do Brasil estima-se que os dados apresentados, apesar de expressivos para os setores da indústria, não definem a real proporção do fenômeno. Não se podem desconsiderar práticas altamente disseminadas e controversas, entre as quais a pirataria se destaca (CRUZ JUNIOR E CRUZ, 2016). Para Cruz Júnior e Cruz (2016) a pirataria é uma temática cuja discussão permeia dois polos distintos: o primeiro trata a pirataria como uma prática ilícita,

\footnotetext{
${ }^{7}$ Informações disponíveis no Relatório do Mercado Global de Games do ano de 2016. Disponível em: http://resources.newzoo.com/thank-you-global-games-market-report-light?submissionGuid=bb0ba170082d-4c61-8aca-a0ad0d7fbb57 . Acesso em: 28 mar. 2017.

${ }^{8}$ Dados em: $<$ http://www.bndes.gov.br/SiteBNDES/export/sites/default/bndes_pt/Galerias/Arquivos/produtos/dow nload/aep_fep/chamada_publica_FEP0211_mapeamento_da_industria.pdf $>$. Acesso em: 21 mar. 2018.
} 
prejudicial ao sistema, que deve ser combatida e o segundo que entende a pirataria como uma maneira de ampliar o acesso aos bens culturais para quem não está disposto a arcar com os custos dos produtos originais.

Nesse sentido, o imaginário que abrange o conjunto de significados atribuídos às ações dessa natureza tem se configurado como terreno de disputa: de um lado encontram-se os esforços de criminalização movidos pelo Estado e pelas indústrias do entretenimento; e de outro as aspirações libertárias amparadas por parcela significativa dos cidadãos, especialmente dos segmentos juvenis (CRUZ JUNIOR; CRUZ, 2016, p. $183)$.

Segundo Junior e Cruz (2016) o Brasil é um país que tem um dos contextos mais adversos para o consumo de jogos digitais, devido às taxas tributárias embutidas nos seus produtos. Entretanto, está cada vez mais significativo o movimento de difusão cultural dos jogos digitais.

Os jogos digitais não são consumidos somente por jovens do sexo masculino, como se pensa tradicionalmente, mas também por crianças, mulheres e idosos. Além disso, o uso dos jogos digitais e as tecnologias que tal setor concebe ultrapassam o entretenimento. São incorporados a atividades de educação, a pesquisas cientificas, a treinamentos (desde o âmbito corporativo até a Defesa Nacional), além de serem usados na capacitação para o atendimento de saúde, na escolha e desenvolvimento de vocações, na arquitetura e construção civil ${ }^{9}$.

Esses jogos digitais que simulam situações práticas do dia-a-dia, com a finalidade de educar, formar, proporcionar conhecimento, treinar e/ou desenvolver

\footnotetext{
${ }^{9}$ Informação disponível em: $<$ http://www.bndes.gov.br/SiteBNDES/export/sites/default/bndes pt/Galerias/Arquivos/produto s/download/aep_fep/chamada_publica_FEP0211_mapeamento_da_industria.pdf $>$. Acesso em: 21 mar. 2018
} 
competências que extrapolam a ideia de entretenimento e oferecem outros tipos de experiências, são considerados serious games (ZYDA, 2005).

Por ser uma prática cada vez mais presente no mundo contemporâneo, muito se discute a respeito das interfaces entre os jogos tradicionais e os jogos digitais. Antes de mais nada, os jogos digitais são considerados jogos (REIS; CAVICHIOLLI, 2015), desprovidos de definições unívocas e verdades absolutas (CRUZ JUNIOR, 2014).

Para Huizinga (2008) o jogo está presente em todos os âmbitos da vida em sociedade: nas artes, nos rituais religiosos, na política, nas leis e nas interações sociais entre os indivíduos. $\mathrm{O}$ autor define jogo como

[...] uma atividade ou ocupação voluntária, exercida dentro de certos e determinados limites de tempo e de espaço, segundo regras livremente consentidas, mas absolutamente obrigatórias, dotado de um fim em si mesmo, acompanhado de um sentimento de tensão e de alegria e uma consciência de ser diferente da "vida cotidiana" (p. 34).

Compreender os significados do jogo tem se colocado enquanto um grande desafio em diferentes perspectivas, seja em sua dimensão filosófica, sociocultural, psicológica e pedagógica (HUIZINGA, 2008; CAILLOIS, 1990). Com a evolução do espaço virtual por meio da cultura digital diferentes reflexões filosóficas e psicológicas, bem como mudanças nas relações socioculturais e pedagógicas, foram incorporadas ao que chamamos de jogo, dificultando ainda mais a sua significação.

Concordamos com Mendes (2006, p. 21) quando nos diz que "descrever o que é um jogo digital passa por atualizações momentâneas relacionadas ao avanço da informática”. Para Reis e Cavichiolli (2014, p. 312) os jogos digitais são

[...] produtos culturais contemporâneos utilizados principalmente como motor de experiências lúdicas vivenciadas no chamado tempo de lazer. Ainda que utilizados para finalidades terapêuticas, educativas ou instrumentais, sua 
principal função realmente tem sido, desde sua invenção, propiciar diversão, distração e entretenimento.

Entretanto, para um melhor entendimento do universo deste artigo é necessário esclarecer que existem jogos digitais no qual o jogador participa por meio da interação corporal de movimento. Esses jogos surgem a partir da década de 90 e permitem que o jogador, por meio de movimentos amplos, execute os comandos do jogo (FINCO E FRAGA, 2013). Esse tipo de jogo digital deixa de ser

[...] controlado apenas pela ponta dos dedos em contato com o joystick e passa a ser controlado pelo corpo inteiro: esquivar, rebolar, lançar, golpear, entre outros, tornaram-se os novos comandos que interagiam diretamente com o propósito dos jogos (FINCO e FRAGA, 2013, p.4).

Essa nova possibilidade de interação adquire diversas denominações, tais como: exergames (EXG), exergaming, activity-promoting video games, physically interactive video game, active video gaming, motion-sensing video game, activity promoting computer games, active video games, entre outras. Ao longo deste artigo será utilizada a expressão exergame (EXG), por ser uma das mais empregadas na literatura (BARACHO; GRIPP e LIMA 2012). Além disso, vale ressaltar que será utilizada a terminologia jogos digitais, ao invés de videogame, jogo eletrônico, games, entre outras terminologias, por ser mais abrangente e representar todo e qualquer tipo de jogo que se mobiliza ou se sustenta em tecnologias digitais, desde videogames até jogos de computador (CRUZ JUNIOR, 2014).

Ao se voltar o olhar para o contexto específico dos exergames percebe-se que a dança, foco de atenção deste estudo, foi pioneira nessa abordagem. Também se observa que esses recursos tecnológicos já expressam novas tendências, ampliando, 
sobremaneira, as possibilidades de experiências enquanto corpos dançantes, tema este, que será abordado no próximo tópico.

\section{A dança e os Jogos Digitais}

O primeiro jogo específico de dança foi lançado em 1998 pela empresa japonesa Konami e recebeu o nome de Dance Dance Revolution e utilizava uma máquina designadas Máquina para Dança $(\mathrm{MpD})$. Esses jogos foram a princípio criados para plataforma arcade, também conhecida como fliperama.

Esses equipamentos eram grandes, compostos de gabinete, tela, processador, amplificadores de som e um piso acoplado ao processador. Especificamente nessa máquina o jogador se movimentava sobre o piso seguindo as setas luminosas, ao ritmo de uma música e a codificação do movimento era feita por meio de interfaces de contato dos pés do jogador com o piso.

As Máquinas para Dança (MpD) ainda são encontradas em estações de jogos eletrônicos de centros comerciais e outros estabelecimentos de entretenimento e, por essa razão, estende sua reflexão também às conexões que a dança estabelece com o jogo

(MENDES, 2013). Nas MpD acontecem campeonatos de dança em

[...] duas modalidades de jogo: o modo velocidade (speed), pautado na resposta corporal, veloz e eficiente, aos comandos de movimento trazidos pela programação do jogo, e o modo estilo livre (freestyle), onde são considerados critérios de criação e inventividade na execução dos movimentos. Dentro de cada versão da máquina há, ainda, diferentes modos de jogo, a exemplo de: easy (fácil) e normal, para iniciantes; hard (difícil), crazy (louco), nightmare (pesadelo), entre outros, para os especialistas (MENDES, 2013, p. 12).

Esses jogos, mesmo não concebidos com as tecnologias de captura de movimento mais recentes, continuam exercendo atração sobre a juventude, no Brasil e 
no mundo. A MpD, que a princípio foi criada para plataforma arcade (fliperamas), é disponibilizada, a partir de 2005, para a versão em consoles domésticos, substituindo a grande máquina por um tapete de contato (MENDES, 2013).

Tanto na versão arcade quanto na versão para o console, a codificação do movimento se mantem por meio de interfaces de contato no piso da plataforma (arcade) ou no tapete de contato (console). Ao longo do jogo, o jogador pressiona as setas de forma sincronizada com a música e ao final recebe uma pontuação baseada no quanto consegue acompanhar as setas da tela, com movimentos correspondentes dos pés (PEREIRA, 2012).

A tecnologia dos jogos digitais de dança diversificou-se bastante desde os primeiros jogos lançados. No ano de 2006 a empresa Nintendo lançou um jogo digital com um controle sem fio que captava o movimento que se fazia com o controle, denominado Nitendo Wii. Já no ano de 2010 foi a empresa Microsoft que inovou, lançando o Kinect para o Xbox. Um sensor de movimentos que permiti aos jogadores interagirem com os jogos digitais sem a necessidade de ter em mãos um controle/joystick, inovando no campo da jogabilidade da dança.

Atualmente, a figura da grande máquina foi dissolvida e os jogos digitais de interação corporal (exergames) de dança dispensam pisos, tapetes ou qualquer tipo de interface de contato e são fundamentados na tecnologia de captura de movimento. Tal tecnologia, envolvendo todo o corpo, expande o espaço disponível ao jogo, anteriormente restrito ao piso de setas, e reduz o espaço da máquina em si (MENDES, 2013).

Dentre as possibilidades de jogos digitais de dança que utilizam a tecnologia de captura de movimento, está o Just Dance, um exergame lançado no ano de 2009, pela 
empresa francesa Ubisoft ${ }^{10}$. O Just Dance é um jogo digital de dança que se baseia em imitar a coreografia de um dançarino virtual na tela.

No ano de 2015 a Ubisoft anunciou e disponibilizou para o Brasil o jogo Just Dance 2015, que surgiu com duas características interessantes: a criação de uma comunidade virtual denominada "Community remix" e a possibilidade de ser um jogo multiplataforma.

A comunidade virtual denominada "Community remix" proporciona a interação entre jogadores do mundo inteiro e [...] se organiza sobre uma base de afinidade, por intermédio de sistemas de comunicação telemáticos [...] (LÉVY 1996, p.20) onde seus componentes se reúnem pelos mesmos núcleos de interesses. Redes de comunicação trocas de informações e aprendizado giram em torno desses jogos e seus adeptos, constituindo comunidades específicas para esse fim. Além do componente de diversão pessoal, tais jogos trazem uma forma de interação social específica e são muito difundidos pelas juventudes nos dias de hoje (JIH-HSUAN, 2017).

Já a possibilidade de ser um jogo multiplataforma potencializou a sua jogabilidade. Esse tipo de jogo é feito para rodar em vários dispositivos. Por ser o mesmo jogo, a experiência de jogá-lo precisa ser consistente, parecida, ou até mesmo idêntica, independentemente da plataforma. Além disso, características fundamentais como o nome, a mecânica básica de jogo e o tema também devem ser os mesmos ${ }^{11}$.

Por ser um jogo multiplataforma pode ser usado nos mais variados consoles (Wi, Playstation, Xbox) e em qualquer tela que conecte a um navegador de internet (PC, TV,

\footnotetext{
${ }^{10}$ Em 1986 foi criada na França a Ubisoft, que, com o sucesso de seus jogos, rapidamente expandiu suas atividades para o Reino Unido, Alemanha e Suíça, além de Estados Unidos e Japão. Na França, a Ubisoft, desenvolvedora de jogos para consoles, tem sede em Motreuil, subúrbio de Paris.

${ }^{11}$ Disponível

em: https://www.bndes.gov.br/SiteBNDES/export/sites/default/bndes_pt/Galerias/Arquivos/produtos/downloa d/aep_fep/chamada_publica_FEP0211_mapeamento_da_industria.pdf. Acesso em: 18 mar. 2018.
} 
etc.). A versão do jogo nas plataformas da Nintendo e Playstation necessita de um controle sem fio individual e, em alguns casos, de uma câmera para capturar os movimentos do jogador. Na versão do jogo para a plataforma Xbox um sensor de movimentos, denominado Kinect - com uma câmera que permite o reconhecimento facial da pessoa que está em frente do console e um sensor de profundidade infravermelho, que permite que o acessório scaneie o ambiente a sua volta em três dimensões -, permite que os jogadores interajam com o jogo, sem a necessidade de ter em mãos um controle, trazendo os comandos para esfera gestual.

Já a possibilidade de se jogar em qualquer tela conectada à internet, funciona a partir da página oficial do jogo ${ }^{12}$ e do aplicativo de download gratuito (disponível para IOS e Androide), denominado Just Dance Now. Neste caso, não será necessário o uso do console e não haverá limitação em relação ao número de pessoas que poderão jogar ao mesmo tempo. O jogador deverá acessar a página do Just Dance Now e acompanhar as coreografias utilizando o celular nas mãos para rastrear os movimentos enquanto realiza os passos de dança ${ }^{13}$.

Cruz Junior (2017) destaca o protagonismo das tecnologias móveis tanto na afirmação de um status híbrido da corporeidade, quanto na aceleração de transformações no âmbito da ludicidade. O autor nos aponta que a dissociação entre espaço e tempo provocada pela disseminação dessas tecnologias móveis torna cada vez mais difícil delimitar hora e lugar corretos para essas práticas digitais. "Entre os desdobramentos da dissolução da unidade espaço-tempo, está o enfraquecimento do círculo mágico enquanto barreira que separa o jogo e o não jogo" (CRUZ JUNIOR,

\footnotetext{
${ }^{12}$ Página oficial do Just Dance Now disponível em: www.justdancenow.com. Acesso em 18 de março de 2018.

${ }^{13}$ Disponível

em: $<$ https://play.google.com/store/apps/details?id=com.ubisoft.dance.justdance2015companion\&hl=pt_B $\mathrm{R}>$. Acesso em 15 de março de 2018.
} 
2017, p. 395). A noção de círculo mágico apresentada pelo autor é inspirada no conceito de Huizinga (2008) e estabelece uma forma de demarcar o espaço-tempo em que o jogo acontece, além de uma maneira de sublinhar a separação entre vida cotidiana e faz-deconta.

No jogo Just Dance também é permitido errar sem a música ser interrompida. Assim, a fruição do jogo não depende dos acertos ou erros do jogador, que na verdade, influenciarão apenas na pontuação ao final da música. Ao contrário de outros jogos digitais de dança em que a música é interrompida com o erro do jogador, o prazer de jogar um jogo que não é interrompido quando se realiza um movimento incorreto tornase determinante no sucesso desses jogos de dança. Muitas vezes, a busca incessante pela técnica pode diminuir o aspecto lúdico e o prazer que o acompanha (ASSIS; CORREIA 2006). Nessa perspectiva, o ato de dançar possibilita aprofundar-se em uma vivência lúdica e mesmo que o jogador não saiba realizar o movimento corretamente o jogo flui normalmente, o que pode contribuir para que dance sem se preocupar com a performance durante o jogo.

O Just Dance possibilita o compartilhamento de vídeos na internet. Ao final de cada coreografia, um pequeno vídeo, mostrando alguns trechos da dança é criado automaticamente. Esse vídeo poderá ser compartilhado pelo próprio jogador no Facebook ou poderá ser salvo na memória do console ${ }^{14}$.

O Just Dance também possibilita a criação de clipes utilizando as músicas do jogo, sendo a gravação feita por meio da câmera do próprio console ou kinect ${ }^{15}$. Esses clipes gravados, ao serem compartilhados em redes sociais e canais do youtube

14 Disponível em: https://www.voxel.com.br/jogo/just-dance-2015/analise.htm . Acesso em: 19 mar. 2018.

${ }^{15}$ Informação disponível em: <https://games.tecmundo.com.br/noticias/estrela-voce-modo-showtime-justdance-2016-permite-gravar-clipes_813286.htm>. Acesso em: 18 maio 2017. 
possibilitam que outras pessoas tenham acesso às coreografias e simulem a prática do jogo. A simulação da prática do jogo é incentivada pela própria empresa, que compartilha vídeos oficiais das coreografias no youtube. Nesse sentido, as pessoas podem simplesmente dançar, seguindo o jogo na tela do computador ou da TV. O conteúdo é o mesmo, e a única diferença é a ausência de retroalimentação personalizada do sistema do jogo. Por exemplo, em jogos interativos, o feedback (por exemplo, " perfeito ", " ok " ou " errado") aparece na tela, enquanto dançar em um vídeo do youTube não exibe um feedback sobre seu desempenho (JIH-HSUAN, 2017).

A Ubisoft, empresa desenvolvedora do jogo, promove anualmente, desde o ano de 2014, uma competição mundial, intitulada Copa do Mundo de Just Dance. As seletivas brasileiras acontecem em duas modalidades distintas: presencial e online. A modalidade presencial acontece em um evento itinerante, denominado Just Dance Tour, que percorre seis estados brasileiros ${ }^{16}$, e garante aos vencedores e vices, de cada estado, um lugar na final nacional. Já a modalidade online seleciona dois jogadores para a final nacional e acontece dentro do próprio jogo, na plataforma de interação virtual, denominada World Dance Floor. Todos os doze jogadores selecionados nas seletivas estaduais mais os dois jogadores selecionados na seletiva online participam do Campeonato Brasileiro de Just Dance (presencial) e o vencedor leva a vaga para representar o país na Copa do Mundo de Just Dance, que acontece na cidade de Paris (França), sede da Ubisoft ${ }^{17}$.

\footnotetext{
${ }^{16}$ As etapas classificatórias do Just Dance Tour 2017 aconteceram nas cidades de Belém/PA, Belo Horizonte/MG, Fortaleza/CE, Recife/PE, Rio de Janeiro/RJ e São Paulo/SP. A final aconteceu na feira Comic Con Experience em São Paulo, no dia 9 de dezembro de 2017. Disponível em: $<$ https://br.ign.com/just-dance-2018/56371/news/finais-do-just-dance-tour-serao-realizadas-na-comiccon-expe.> Acesso em: 21 mar. 2018.

${ }^{17}$ Disponível em: $<$ https://br.ign.com/just-dance-2018/56371/news/finais-do-just-dance-tour-seraorealizadas-na-comic-con-expe> . Acesso em: 21 mar. 2018.
} 
A dança é abordada nessa perspectiva como uma atividade competitiva e esportivizada onde as pessoas envolvidas estão submetidas constantemente a um verdadeiro bombardeio de observações, opiniões e julgamentos. Nesses encontros a competição acaba tornando-se o motivo e o fim pelo qual se dança e a experiência produzida por esses campeonatos podem apontar uma tendência de esportivização da dança (ASSIS; CORREIA, 2006), proporcionada por meio da tecnologia digital.

Outro fator importante para as comunidades de jogadores é a presença da música. A cada nova versão os jogadores esperam ansiosamente a divulgação das listas em construção, e, mesmo antes do novo lançamento, começam a ouvir e a dançar tais músicas, aumentando a expectativa pelas rotinas de movimento que comporão o novo jogo (SMITH, 2004 apud MENDES, 2013). A simbiose entre a cultura pop e os recursos tecnológicos se manifesta como um fator decisivo no processo de imersão e de sedução dos jogadores (CRUZ JUNIOR, 2017).

Atualmente, podemos encontrar jogos com uma grande variedade de estilos musicais, fornecendo as mais recentes canções pop e clássicas com vários estilos de dança e diferentes níveis de dificuldade (JIH-HSUAN, 2017). Da primeira edição do Just Dance até a versão do ano de 2018 foram lançadas oito músicas que fazem menção ao Brasil. A escolha das narrativas que representam o país no jogo destaca canções de samba, axé, funk e pop nacional. Entre essas narrativas que circulam no universo desse jogo digital percebe-se uma alusão corporal ao samba brasileiro que reflete o modo como a nossa cultura é percebida pelo olhar do estrangeiro (SCHEYERL; SIQUEIRA, 2008).

No Just Dance equipamentos providos de tecnologia de leitura de movimento “observam” o jogador em ação e confrontam seus gestos aos do dançarino virtual 
exibido na tela. O comando do movimento, nesse caso, não vem de um código alheio ao próprio movimento (as setas), mas de uma imagem antropomórfica à qual se procura imitar (MENDES, 2013). O fato dos avatares, verdadeiros corpos virtuais, desenhados e programados para a interação no espaço virtual (GUIMARAES JUNIOR, 2004), reproduzirem uma rotina que deverá ser imitada pelo jogador, fazem com que os jogos digitais sejam vistos, com certo preconceito na área da dança.

Os jogos digitais de dança são atacados pelo discurso de serem antipedagógicos, viciantes e por incorporarem movimentos repetitivos. A superação dessa interpretação simplista, proporciona aos jogadores novas formas de se mover mesmo que partindo da repetição e encadeamento. "Repetir, repetir, até deixar de ser repetição" (MENDES, 2013 p. 95), para gerar uma apropriação e/ou domínio do movimento, que libertará e impulsionará para novas possibilidades. Serres (2004 apud MENDES, 2013) nos mostra que a imitação é uma das fases do processo de conhecimento. Quanto mais se imita, mais se é capaz de conhecer. Para o autor o corpo imita, armazena, lembra e, inesperadamente, inventa. No entanto, para que a invenção aconteça, é preciso condições adequadas de liberdade, para que a imitação não se reduza à obediência (SERRES, 2004 apud MENDES, 2013).

Para o antropólogo alemão Wulf (2005, p.175) “o ato mimético não é mera reprodução, mas ação criativa". Na dança e em outras artes como a música o autor aponta a possibilidade de aproximação entre a representação e a criação expressiva, dizendo que "representar alguma coisa significa também exprimir alguma coisa" (WULF, 2005, p. 83), uma espécie de representação que já exige criação.

Para Mendes (2013) o uso pedagógico dessas novas tecnologias para aprendizagem da dança está pautado nas possibilidades potencializadoras da dança pelo 
jogo digital, uma vez que “[...] a habilidade de dançar se constrói através do sensório motor do corpo, que como qualquer outro organismo, se transforma pela informação que agrega" (KARTZ, 2010, p. 77).

As experiências dançantes são fruto de corpos (aparato motor, capacidades mentais, fluxo emocional), de interações com o ambiente (se mover, manipular objetos) e de interações com outras pessoas dentro de uma determinada cultura (em termos sociais, políticos, religiosos) e fora dela. (KARTZ; GREINER, 2006). Nesse sentido, o ato de dançar "é o de estabelecer relações testadas pelo corpo em uma situação, em termos de outra, produzindo nesse sentido, novas possibilidades de movimento[...]" (KARTZ; GREINER, 2006, p. 132).

Nessa interação com as tecnologias digitais, a dança se afirma como uma autêntica forma de expressão humana, presente na vida de todas as sociedades, em todos os tempos. De acordo com Garaudy (1980) "dançar é vivenciar e exprimir, com o máximo de intensidade, a relação do homem com a natureza, com a sociedade [...]" (p.14). Para esse autor, a dança é um modo de ser e existir no mundo. Não é apenas uma arte, é um modo de viver.

A dança é uma linguagem social que tem como uma de suas funções a diversão e o prazer (ROBATTO, 1994). Para Mendes (2013), devemos nos posicionar diante das tensões da atualidade e caracterizar a dança como um movimento artístico desprovido de limitações de qualquer ordem, rico em multiplicidades e fragmentações.

\section{Game Over}

No âmbito dos jogos digitais de dança as pessoas dançam, jogam, jogam e dançam. "Dançam as músicas delas, do jeito delas, mas elas dançam. Começar por 
descobrir as representações dos grupos e as possibilidades de inventar e reinventar a dança pode ser o início de uma bela coreografia” (MOITA, 2004, p.11). Portanto, espera-se com esse trabalho ter situado a dança na perspectiva do mundo moderno identificando mudanças, decifrando continuidades e reconhecendo diversidades.

Ao se voltar o olhar para o contexto específico dos jogos digitais de dança, foco de atenção deste estudo, percebe-se que esses recursos tecnológicos já expressam novas tendências, ampliando, sobremaneira, as possibilidades de experiências enquanto corpos dançantes. Os jogos digitais de dança podem proporcionar conhecimento do corpo, de suas habilidades, potencialidades e limites para se chegar a capacidade de transformação e de criação de movimentos.

Espera-se que esta pesquisa tenha identificado os significados dessa prática no meio digital, entendendo que diferentes indivíduos, em diferentes contextos, podem dar sentidos diferentes a uma mesma prática de jogo digital. Outros estudos devem ser realizados, visto que, a prática de jogos digitais de dança é uma realidade cada vez mais presente no nosso dia a dia.

\section{REFERÊNCIAS}

ASSIS, Monique; CORREIA, Adriana Martins. Entre o jogo estético e o impulso lúdico: um ensaio de dança. Revista Brasileira de Ciências do Esporte, Campinas, v. 27, n. 2, p. 121-130, jan. 2006.

ASSUNÇÃO, Alysson Bruno M. Música, Entretenimento e Cognição: análise comparativa dos videogames Guitar Hero III e Rocksmith. Contemporânea, Rio de Janeiro, v. 10, n. 2, p. 119 a 136, 2012.

AMOROSO, Daniela Maria. Dançando com as máquinas: um olhar para o corpo na dança e a tecnologia na sociedade através de um espetáculo de dança-tecnologia. Dissertação (Mestrado). Pós-Graduação em Política Científica e Tecnológica. São Paulo: Unicamp, 2004. 
BARACHO, Ana Flávia de Oliveira; GRIPP, Fernando Joaquim; LIMA, Márcio Roberto de. Os exergames e a educação física escolar na cultura digital. Revista Brasileira de Ciências do Esporte, Florianópolis, v. 34, n. 1, jan./mar. 2012.

CAILLOIS, Roger. Os Jogos e os Homens: a máscara e a vertigem. (Tradução de José Garcês Palha). Lisboa: Cotovia, 1990.

CHAVES, Elisângela.; SILVA, Natália de Oliveira. A dança nos programas de esporte e lazer da cidade. In: CONBRACE, 20 e CONICE, 7, 2017, Goiania. Anais... 2017.

CRUZ JUNIOR, Gilson. Burlando o círculo mágico: o esporte no bojo da gamificação. Movimento (ESEF/UFRGS), v. 20, n. 3, 2014.

. Temos que pegar? Pokémon go e as interfaces entre movimento e jogos digitais. In: CONBRACE, 20 e CONICE, 7, 2017, Goiania. Anais... 2017.

; CRUZ, Dulce Márcia. Quando a brincadeira vira coisa séria: dos mitos e (in)verdades sobre as relações entre jogos digitais, cultura e consumo. Rev Bras Ciênc Esporte, v. 38, n. 2, p.179-185, 2016.

FINCO, Mateus David; FRAGA, Alex Branco. Corpo joystick: cinema, videogames e estilo de vida ativo. LICERE, Belo Horizonte, v. 16, n. 3, 2013.

FOUCAULT, Michel. Sobre a história da sexualidade. In: Machado, R. (Org). Microfísica do Poder. Rio de Janeiro: Graal, 1996 apud MENDES, Cláudio. Lúcio. Jogos eletrônicos: diversão, poder e subjetivação. Campinas: Papirus, 2006.

FRAGOSO, Aline Renata de Farias; BRASILEIRO, Lívia Teonorio. Produção de conhecimento sobre dança e educação nos periódicos brasileiros da educação física. In: COMBRACE, 19 e CONNICE, 6, 2015. Anais...2015.

GARAUDY, D. Dançar a vida. 4. ed. Rio de Janeiro: Nova Fronteira, 1980.

GARCIA, Ângela; HAAS, Aline Nogueira. Ritmo e dança. Santa Maria: Editora da ULBRA, 2003.

GOMES, Christianne Luce. Lazer, economia criativa e indústrias culturais e criativas: onde está o social? Licere, Belo Horizonte, v.17, n.4, dez/2015.

GUIMARÃES JÚNIOR, Mário, J. L. De pés descalços no ciberespaço: tecnologia e cultura no cotidiano de um grupo social on-line. Horizontes Antropológicos, Porto Alegre, ano 10, n. 21, p. 123-154, jan./jun. 2004.

HUIZINGA, Johan. Homo ludens: o jogo como elemento da cultura. 5. ed. São Paulo: Perspectiva, 2008. 
JIH-HSUAN, Lin. "Just Dance": The Effects of Exergame Feedback and Controller Use on Physical Activity and Psychological Outcomes. Games for Health Journal. April2015. Disponível em: $<$ https://online.liebertpub.com/doi/pdf/10.1089/g4h.2014.0092> Acesso em: 20 Jan. 2017.

KARTZ, Helena. O corpo que dança. In: GREINER, Christine; AMORIM, Claudia (Org.). Leituras do corpo. São Paulo: Annablume, 2010.

; GREINER, Christine. Por uma teoria do corpomídia. In: GREINER, Christine. O Corpo: pista para estudos indisciplinares. São Paulo: Annablume, 2006.

LABAN, Rudolf. Dança educativa moderna. São Paulo: Ícone, 1990.

LÉVY, Pierre. O que é o virtual? São Paulo: Editora 34, 1996.

MARQUES, Isabel A. Dançando na escola. 5. ed. São Paulo: Cortez, 2010.

MENDES, Ana Carolina de S. S. D. Autonomia e conexões em dança: um diálogo com a tecnologia e o jogo. Tese (doutorado). Universidade de Brasília. Instituto de Artes Visuais. Programa de Pós-Graduação em Artes. Brasília, 2013.

MENDES, Cláudio. Lúcio. Jogos eletrônicos: diversão, poder e subjetivação. Campinas: Papirus, 2006.

MINELlO, Daniela. A dança e as práticas educativas: uma experiência corporal reflexiva na formação de professores. Dissertação (Mestrado). Universidade Federal de Santa Maria. Centro de Educação. Programa de Pós-Graduação em Educação. RS: 2006.

MOITA, Filomena. Juventude e jogos eletrônicos: que currículo é esse? Universidade Federal da Paraíba, 2004. Disponível em: <https://bocc.ubi.pt/pag/moita-filomenajogos-electronicos.pdf $>$ Acesso em: 18 abr. 2015.

MULLER, Ana Cristina Nunes Gomes; CRUZ, Dulce Márcia. Formação docente para inclusão de games na educação básica: relato de uma experiência. Obra digital: revista de comunicación, Catalunya, n. 10, Fev/2016.

NANNI, Dionísia. DANÇA Educação: pré-escola à universidade. Rio de Janeiro: Sprint, 1995.

PEREIRA, Omar Calazans Nogueira. Jogar Videogame como uma experiência simbólica: entrevistas com jogadores. Boletim de Psicologia, v. 62, n. 136, p. 81-91, 2012.

PORTINARI, Maribel. História da Dança. Nova Fronteira. Rio de Janeiro. 1989

REIS, Leôncio José de Almeida; CAVICHIOLLI, Fernando Renato. Dos single aos multiplayers: a história dos jogos digitais. Licere, Belo Horizonte, v.17, n.2, jun/2014. 
Lazer e jogos digitais: reflexões a partir do World of Warcraft. Licere, Belo Horizonte, v. 18, n. 1, 2015.

ROBATTO, Lia. Dança em processo: a linguagem do indizível. Salvador: UFBA, 1994.

SANTOS, Jussara Belchior et al. A jogabilidade em embodied voodoo game. Disponível

em: https://www.gsigma.ufsc.br/ popov/aulas/Publicacoes/Santos_Pinheiro_Zambiasi_SPG UFSC_2012.pdf Acesso em: 19 abr. 2015.

SCHEYERL, Denise; SIQUEIRA, Sávio. O Brasil pelo olhar do outro: representações de estrangeiros sobre os brasileiros de hoje. Trab. Ling. Aplic., Campinas, v. 47, n. 2 , p. 375-391, Jul./Dez, 2008

SERRES, Michel. Variações sobre o corpo. Rio de Janeiro: Bertrand Brasil, 2004 apud MENDES, Ana Carolina de S. S. D. Autonomia e conexões em dança: um diálogo com a tecnologia e o jogo. Tese (doutorado). Universidade de Brasília. Instituto de Artes Visuais. Programa de Pós-Graduação em Artes. Brasília, 2013.

SMITH, Jacob. I Can See Tomorrow In Your Dance: a study of Dance Dance Revolution and music video games. Journal of Popular Music Studies, v.16, Abril, 2004, p.58 - 84 apud MENDES, Ana Carolina de S. S. D. Autonomia e conexões em dança: um diálogo com a tecnologia e o jogo. Tese (doutorado). Universidade de Brasília. Instituto de Artes Visuais. Programa de Pós-Graduação em Artes. Brasília, 2013.

WULF, Chistoph. Antropologia da educação. Tradução de Sidney Reinaldo da Silva. Campinas: Editora Alínea, 2005.

ZYDA, Michael. From visual simulation to virtual reality to games. Computer, v. 38, n. 9, p. 25-32, 2005.

\section{Endereço da Autora:}

Paola Luzia Gomes Prudente

Praça Itajaí, N. 52, Monte Castelo

Contagem - MG - 32.285-190

Endereço Eletrônico: paolag@ymail.com 